\title{
HUBUNGAN ANTARA PERAN KELUARGA SEBAGAI PENGAWAS MINUM OBAT (PMO) DENGAN TINGKAT KEPATUHAN PASIEN TB PARU TERHADAP PROGRAM PENGOBATAN DI WILAYAH PUSKESMAS SERPONG 1 KOTA TANGERANG SELATAN
}

\author{
${ }^{1}$ Dewi Fitriani, ${ }^{2}$ Gita Ayuningtyas \\ Program Studi S1 Keperawatan STIKes Widya Dharma Husada Tangerang \\ Jalan Pajajaran No 1 Pamulang Tangerang Selatan Banten \\ ${ }^{1}$ Email: dewifitriani1717@gmail.com
}

\begin{abstract}
ABSTRAK
Pada tahun 2014, TB telah membunuh 1,5 juta orang, WHO memperkirakan terdapat 9,6 juta kasus TB pada tahun 2014 namun hanya 6 juta kasus yang terlaporkan, artinya terdapat 3,6 juta kasus yang tidak terdiagnosis atau tidak terlaporkan. Sementara itu, 58\% kasus TB dunia diantaranya terdapat di Asia Tenggara dan Pasifik Barat. Indonesia menempati posisi terbesar kedua kasus TB setelah India 23\% yaitu sebesar 10\%. Tingginya kegagalan/ketidakpatuhan program pengobatan juga disebabkan oleh rendahnya pengetahuan pasien tentang lamanya waktu pengobatan, banyaknya obat yang harus diminum, efek samping dari obat TB, hilangnya tanda dan gejala klinis sebelum akhir pengobatan, serta kurangnya dukungan dan motivasi dari keluarga selama pasien menjalani pengobatan. Dampaknya pasien menjadi lebih lama menjalani program, resiko penularan semakin besar, resisten terhadap obat. Keberhasilan dari konversi BTA sangat ditentukan oleh pengobatan secara teratur. Tujuan penelitian : untuk mengetahui hubungan antara peran keluarga sebagai Pengawas Minum Obat (PMO) dengan tingkat kepatuhan pasien TB Paru terhadap program pengobatan di Wilayah Puskesmas Serpong 1 Kota Tangerang Selatan. Metode penelitian : menggunakan desain deskriptif analatik dengan pendekatan cross sectional, jumlah sampel berjumlah 120 orang, pengambilan sampel menggunakan cara Total Sampling dan pengumpulan data menggunakan kuesioner dan wawancara. Hasil penelitian : diperoleh adanya hubungan antara peran keluarga sebagai pengawas minum obat dengan tingkat kepatuhan pasien TB Paru terhadap program pengobatan di wilayah puskesmas Serpong 1 Tangerang Selatan $(\mathrm{p}=0,001)$ Ha diterima. Kesimpulan: adanya hubungan antara peran keluarga sebagai pengawas minum obat dengan tingkat kepatuhan pasien TB Paru terhadap program pengobatan di wilayah puskesmas Serpong 1 Tangerang Selatan.

Kata Kunci : Keluarga Sebagai Pengawas Minum Obat (PMO), Tingkat Kepatuhan Pasien,Tuberkulosis paru
\end{abstract}

\section{RELATIONSHIP BETWEEN THE FAMILY AS A DRUG SUPERVISOR (PMO) AND THE LEVEL OF COMPLIANCE IN LUNG TB PATIENTS TO TREATMENT PROGRAM IN THE REGENCY OF SERPONG 1 PUBLIC HEALTH CENTER SOUTH OF TANGERANG}

\begin{abstract}
In 2014, TB killed 1.5 million people, WHO estimated that there were 9.6 million TB cases in 2014 but only 6 million cases were reported, meaning there were 3.6 million cases that were undiagnosed or unreported. Meanwhile, 58\% of the world's TB cases are found in Southeast Asia and the Western Pacific. Indonesia occupies the second largest position of TB cases after India 23\% which is equal to 10\%.The high failure / noncompliance of the treatment program is also caused by the lack of patient knowledge about the length of time of treatment, the number of drugs to be taken, the side effects of TB drugs, loss of clinical signs and symptoms before the end of treatment and lack of support and motivation from the family while the patient is undergoing treatment. The impact is the patient becomes longer undergoing the program, the risk of transmission is greater, drug resistant. The success of AFB conversion is largely determined by regular treatment. The purpose of this study : to determine the relationship between the role of the family as a Drug Supervisor (PMO) with the level of compliance of pulmonary TB patients with treatment programs in the Serpong 1 Puskesmas 1 South Tangerang City. Research methods: using analytical descriptive design with cross sectional approach, the number of samples totaling 120 people, sampling using Total Sampling and data collection using questionnaires and interviews. The results of the study: the relationship between the role of the family as the supervisor of taking medication with the level of compliance of pulmonary TB patients to the treatment program in the area of Serpong 1 South Tangerang Health Center $(p=0.001]$. Conclusion : there is a relationship between the role of the family as a supervisor taking medication with the level of compliance of pulmonary TB patients with treatment programs in the area of Serpong 1 South Tangerang.
\end{abstract}




\section{LATAR BELAKANG}

Tuberkulosis paru (TB paru) merupakan permasalahan kesehatan global yang telah menjadi perhatian dunia selama dua dekade terakhir (WHO, 2015). Dimana sebagian besar penderita TB paru adalah usia produktif (15-55 tahun). Pada tahun 2014, TB telah membunuh 1,5 juta orang, $W H O$ memperkirakan terdapat 9,6 juta kasus TB pada tahun 2014 namun hanya enam juta kasus yang terlaporkan, artinya terdapat 3,6 juta kasus yang tidak terdiagnosis atau tidak terlaporkan. Sementara itu, 58\% kasus TB dunia diantaranya terdapat di Asia Tenggara dan Pasifik Barat. Indonesia menempati posisi terbesar kedua kasus TB setelah India $23 \%$ yaitu sebesar $10 \%$ (WHO, 2015).

\section{Riset Dasar Kesehatan (RISKESDAS)} tahun 2013 menyebutkan bahwa prevalensi penduduk Indonesia yang didiagnosis TB paru oleh tenaga kesehatan 2013 sebesar 0,4\%. Prevalensi TB paru di Provinsi Banten sebesar 315 per 100.000 penduduk dimana wilayah dengan prevalensi paling tinggi adalah Kota tangerang Selatan yakni sebesar 1.691 per 100.000 penduduk (Dinkes Banten, 2012).

Di Kota Tangerang Selatan tahun 2015 ditemukan sebanyak 5246 suspek TB paru, dimana 735 kasus diantaranya merupakan kasus Tb paru baru BTA Positif (Dinkes Tangsel, 2015).

Seseorang dapat terkena infeksi tuberculosis tanpa menjadi sakit, uji tuberculin dapat menunjukan hasil yang positif tanpa ada kelainan klinis, radiologis paru dan laboratorium.Apa bila sudah terinfeksi harus segera dicegah untuk berkembang menjadi sakit atau menderita tuberculosis dengan memberikan pengobatan OAT. Panduan pengobatan TB dari WHO menyatakan bahwa untuk pengobatan efektif dan terapeutik dibutuhkan waktu selama 6 bulan (dengan syarat tertentu) dimana tidak diperbolehkan ada kelalaian saat menjalani pengobatan tersebut (WHO, 2013).

Banyak penderita yang tidak patuh terhadap pengobatan karena merasa jenuh dan bosan. Apalagi keluarga yang ada kurang berperan dalam melaksanakan tugas memberikan perawatan pada anggota keluarga yang sakit sehingga banyak pasien yang mengalami kegagalan dalam pengobatan.

Dari berbagai faktor penyebab ketidak patuhan minum obat penderita TB Paru, dapat disimpulkan bahwa faktor manusia, dalam hal ini penderita TB paru sebagai penyebab utama dari ketidak patuhan minum obat (Depkes RI , 2010).

Dari uraian di atas peneliti tertarik untuk mengetahui Hubungan Antara Peran 
Keluarga Sebagai Pengawas Minum Obat (PMO) Dengan Tingkat Kepatuhan Pasien TB Paru Terhadap Program Pengobatan Di Wilayah Puskesmas Serpong 1 Kota Tangerang Selatan.

\section{METODE PENELITIAN}

Penelitian ini merupakan penelitian kuantitatif dengan menggunakan desain penelitian deskriptif analitik dengan studi pendekatan cross sectional. Populasi dalam penelitian ini adalah seluruh pasien yang berkunjung terdiagnosa TB Paru dan berobat ke Poli TB Paru di Puskesmas Serpong 1 Kota Tangerang Selatan.

Sampel pada penelitian ini adalah pasien TB Paru di Wilayah Puskesmas Serpong 1 Kota Tangerang Selatan berjumlah 120 orang, pengambilan sampel menggunakan cara Total Sampling.

Pada penelitian ini peneliti menggunakan alat bantu dengan 6 pertanyaan untuk mewakili karakteristik pasien dan 2lembar observasi untuk menggali informasi mengenai status responden yang tertera pada catatan tahunan kasus TB paru dan peran PMO pasien yang terdiagnosa TB paru Di Wilayah Puskesmas Serpong 1 Kota Tangerang Selatan.

Analisa bivariat dilakukan untuk mengetahui hubungan kemaknaan antara variabel independent tentang peran keluarga
PMO meliputi : Sikap keluarga PMO, Perilaku keluarga PMO, Pengawasan Menelam Obat. Dengan variabel dependent tentang tingkat kepatuhan pasien TB Paru yang disajikan dalam bentuk tabel, dengan alat uji yang digunakan yaitu Chi Square, dari uji statistik biasanya didapatkan nilai statistik uji dan tingkat kemaknaan (p). (Hidayat, 2009).

\section{PEMBAHASAN}

\section{ANALISIS UNIVARIAT}

Tabel 1. Jumlah Pasien TB yang berobat di wilayah Puskesmas Serpong 1

\begin{tabular}{lrr}
\hline Jenis Kelamin & $\mathrm{N}$ & $\%$ \\
\hline Laki-laki & 36 & 51.4 \\
perempuan & 34 & 48.6 \\
Total & 70 & 100.0 \\
\hline
\end{tabular}

Berdasarkan tabel 1 dapat diketahui bahwa pasien TB Paru yang berobat di wilayah Puskesmas Serpong 1 sebagian besar adalah laki-laki $(51,4 \%)$ dan sisanya sebanyak $48,6 \%$ adalah perempuan. Penelitian yang dilakukan oleh Fitriani (2012) menyatakan adanya hubungan antara usia penderita dengan kejadian Tuberkulosis.

TB paru lebih banyak terjadi pada laki-laki dibandingkan wanita karena laki-laki sebagian besar mempunyai kebiasaan merokok. Kebiasaan merokok 
meningkatkan risiko untuk terkena TB paru sebanyak 2,2 kali

Berdasarkan tabel 3 dapat diketahui bahwa pasien TB Paru yang berobat di wilayah Tabel 2. Kategori usia Pasien TB yang berobat di wilayah Puskesmas Serpong 1

\begin{tabular}{lcc}
\hline $\begin{array}{l}\text { Kategori } \\
\text { usia } \\
\text { pasien }\end{array}$ & $\mathrm{n}$ & \\
\hline Anak & 9 & 12.9 \\
remaja & 14 & 20.0 \\
dewasa & 28 & 40.0 \\
Lansia & 19 & 27.1 \\
\hline Total & 70 & 100.0 \\
\hline
\end{tabular}

Berdasarkan tabel 2 dapat diketahui bahwa kategori usia pasien TB Paru yang berobat di wilayah Puskesmas Serpong 1 terbanyak adalah kategori dewasa sebanyak $40 \%$ lalu diikuti oleh kategori lansia sebanyak 27,1\%, kategori remaja sebanyak $20 \%$, lalu sisanya adalah kategori anak-anak sebanyak 12,9\%.

Tabel 3. Distribusi Frekuensi Pasien TB berdasarkan Pekerjaan di wilayah Puskesmas Serpong 1

\begin{tabular}{lcr}
\hline Pekerjaan & $\mathrm{n}$ & $\%$ \\
\hline Pelajar & 16 & 22.9 \\
Ibu rumah tangga & 17 & 24.3 \\
Swasta & 29 & 41.4 \\
pegawai negeri & 2 & 2.9 \\
sipil & 6 & 8.6 \\
tidak bekerja & 6 & 100.0 \\
\hline Total & 70 & \\
\hline
\end{tabular}

Tabel 4. Distribusi frekuensi pendidikan Pasien TB di wilayah Puskesmas Serpong 1

\begin{tabular}{lcc}
\hline Pendidikan & $\mathrm{n}$ & $\%$ \\
\hline pra sekolah & 7 & 10.0 \\
SD & 13 & 18.6 \\
SMP & 8 & 11.4 \\
SMA & 33 & 47.1 \\
D3 & 2 & 2.9 \\
S1 & 7 & 10.0 \\
\hline Total & 70 & 100.0 \\
\hline
\end{tabular}

Berdasarkan tabel 4 dapat diketahui bahwa tingkat pendidikan pasien TB Paru yang berobat di wilayah Puskesmas Serpong 1 terbanyak adalah SMA sebanyak 47\% Tabel 5. Distribusi frekuensi Pasien TB berdasarkan riwayat pengobatan di wilayah Puskesmas Serpong 1

\begin{tabular}{lrr}
\hline Riwayatpengobatan & $\mathrm{n}$ & \multicolumn{1}{c}{$\%$} \\
\hline Pengobatan pertama & 67 & 95.7 \\
Pengobatan kedua & 2 & 2.9 \\
Pengobatan ketiga & 1 & 1.4 \\
\hline Total & 70 & 100.0 \\
\hline
\end{tabular}


Berdasarkan tabel 5 dapat diketahui bahwa riwayat pengobatan TB Paru pada pasien yang berobat di wilayah Puskesmas Serpong 1 terbanyak adalah pengobatan pertama sebanyak $95,7 \%$, sisanya adalah pengobatan kedua sebanyak 2,9\% dan pengobatan ketiga sebanyak $1,4 \%$.

Tabel 6. Distribusi frekuensi peranan keluarga pada Pasien TB di wilayah Puskesmas Serpong 1

\begin{tabular}{lcc}
\hline & $\mathrm{n}$ & $\%$ \\
\hline kurang & 21 & 30.0 \\
baik & 49 & 70.0 \\
\hline Total & 70 & 100.0 \\
\hline
\end{tabular}

Berdasarkan tabel 6 dapat diketahui bahwa peranan keluarga sebagai PMO pada pasien TB Paru di Wilayah Puskesmas Serpong 1 yang dikategorikan "baik" sebanyak 70\% dan sisanya dikategorikan "kurang" sebanyak $30 \%$.

Tabel 7. Distribusi frekuensi kepatuhan minum obat Pasien TB di wilayah Puskesmas Serpong 1

\begin{tabular}{lcc}
\hline $\begin{array}{l}\text { Kepatuhan } \\
\text { minum } \\
\text { obat }\end{array}$ & $\mathrm{n}$ & $\%$ \\
\hline kurang & 19 & 27.2 \\
baik & 51 & 72.8 \\
\hline Total & 70 & 100.0 \\
\hline
\end{tabular}

Berdasarkan tabel 7 dapat diketahui bahwa kepatuhan pasien TB Paru di Wilayah Puskesmas Serpong 1 yang dikategorikan "baik" sebanyak $72,8 \%$ dan sisanya dikategorikan "kurang” sebanyak 27,2\%.

\section{HASIL ANALISA BIVARIAT}

Tabel 8. Hubungan Antara Peran Keluarga Sebagai Pengawas Minum Obat (PMO) Dengan Tingkat KepatuhanPasien TB Paru Terhadap Program Pengobatan Di Wilayah Puskesmas Serpong 1 Tangsel

\begin{tabular}{|c|c|c|c|c|c|c|c|}
\hline \multirow{3}{*}{$\begin{array}{l}\text { Peranan } \\
\text { keluarga }\end{array}$} & \multicolumn{4}{|c|}{ Kepatuhan pasien } & \multirow{2}{*}{\multicolumn{2}{|c|}{ Total }} & \multirow{3}{*}{$\begin{array}{c}\mathrm{P} \\
\text { value }\end{array}$} \\
\hline & \multicolumn{2}{|c|}{ Kurang } & \multicolumn{2}{|c|}{ Baik } & & & \\
\hline & $\mathrm{n}$ & $\%$ & $\mathrm{n}$ & $\%$ & $\mathrm{n}$ & $\%$ & \\
\hline Kurang & 17 & 81,0 & 4 & 19,0 & 21 & 100 & 0,001 \\
\hline Baik & 4 & 8,2 & 45 & 91,8 & 49 & 100 & \\
\hline
\end{tabular}

Berdasarkan tabel 8 menunjukkan bahwa terdapat hubungan antara peran keluarga sebagai pengawas minum obat dengan tingkat kepatuhan pasien TB Paru terhadap program pengobatan di wilayah puskesmas Serpong 1 Tangsel $(\mathrm{p}=0,001)$.

Dari tabel tersebut juga menunjukkan bahwa pasien TB Paru yang patuh terhadap program pengobatan sebanyak 45 orang memiliki dukungan yang baik dari keluarga. Selain itu terdapat 17 pasien TB Paru yang kurang patuh terhadap program pengobatan dan kurang mendapat dukungan dari keluarga.

Limbu dan Marni (2006) menyebutkan peran keluarga dalam bentuk partisipasi terhadap proses pengobatan penderita TB Paru yaitu merujuk penderita ke puskesmas, membawa penderita di tenaga kesehatan, 
membantu penderita pada pemeriksaan di laboratorium, pemenuhan kebutuhan penderita, mengingatkan penderita untuk minum obat dan memberi obat untuk diminum setiap malam dan melakukan pengambilan obat untuk pesediaan, serta mengantarkan penderita malakukan pengontrolan di puskesmas bila selesai minum obat fase intensif ( 2 bulan) sangatlah diperlukan.

Pemilihan PMO diutamakan dari keluarga pasien, karena keluarga adalah orang terdekat yang setiap saat bisa mengawasi pasien pada saat minum obat selain itu karena adanya ikatan batin antara penderita dengan PMO yang berasaldari keluarganya. Berdasarkan hasil penelitian teridentifikasi peran Keluarga sebagai PMO dalam memberikan motivasi atau dorongan agar pasien termotivasi untuk menjalani pengobatan sudah optimal.

Menurut Hanan, M \& Hidayat, S. (2013), keluarga memotivasi pasien akan keteraturan minum obat, kontrol dan pengawasan minum obat. Pemberian motivasi oleh keluarga kepada penderita dalam hal keteraturan obat sebagian besar memberikan motivasi akan pentingnya minum obat, mengingatkan penderita minum obat, obat harus diminum, dan supaya memudahkan penderita dalam minum obat.

Menurut asumsi peneliti, peran keluarga dalam memotivasi pasien TB Paru sangat memberikan dampak yang positif terhadap pengobatan pasien TB Paru. Secara psikologis, kedekatan hubungan batin antara anggota keluarga menjadikan dukungan berupa harapan akan kesembuhan dan keinginan keluarga untuk melihat pasien beraktifitas kembali menjadikan hal tersebut sebagai motivasi kepada pasien.

\section{DAFTAR PUSTAKA}

Astuti. Sumiyati, 2013. Hubungan Tingkat Pengetahuan Dan Sikap Masyarakat Terhadap Upaya Pencegahan Penyakit Tuberkulosis Di RW 04 Kelurahan Lagoa Jakarta Utara Tahun 2013. Jurnal

Departemen Kesehatan Republik Indonesia. 2013. Data Riskesdas tentang TB Paru.

Departemen Kesehatan Republik Indonesia. 2007. Pedoman Pengobatan Dasar di Puskesmas 2007.

Jurnal Persatuan Dokter Paru Indonesia. 2011. Tentang TB Paru.

Muttaqin, Arif. 2008. Buku Ajar Asuhan Keperawatan Klien Dengan Gangguan Sistem Imunologi. Jakarta: Salemba Medika

Notoatmodjo, Soekidjo. 2007. Promosi Kesehatan dan Ilmu Prakit. Jakarta : Rineka Cipta. 
Notoatmodjo, Soekidjo. 2010. Ilmu Perilaku Kesehatan. Jakarta : Rineka Cipta.

Notoatmodjo, Soekidjo. 2011. Kesehatan Masyarakat Ilmu dan Seni. Jakarta : Rineka Cipta.

Notoatmodjo, Soekidjo. 2012. Metodologi Penelitian Kesehatan. Jakarta : Rineka

Cipta.

Rustandi, Apriyana. 2017. Hubungan Tingkat Pengetahuan Pasien Dengan Kepatuhan Minum Obat TB Paru Di Puskesmas Benda Baru Kecamatan Pamulang Kota Tangerang Selatan. Skripsi.

Sahat P Manalu, Helper. 2010. Faktorfaktor Yang Mempengaruhi Kejadian TB Paru dan Upaya Penanggulangannya.

Somantri, Irman. 2007. Asuhan Keperawatan pada Pasien dengan Gangguan Sistem Pernafasan. Jakrta : Salemba Medika.

WHO. 2003. Adherence To Long-Term Therapies Evid Ence For Action

WHO. 2015. Global Tuberculosis Report

Yoisangadji, S. A, dkk, 2016. Hubungan Pengawasan Menelan Obat (PMO) dan Peran Keluarga dengan Kepatuhan Minum Obat pada Pasien di Wilayah Kerja Puskemas Sario Kota Medan.

Fitriani E. 2012. Faktor Risiko yang Berhubungan dengan Kejadian TB paru. Unnes Journal of Public Health. http://journal.unnes.ac.id/ sju/index.php/ujph/article/download /3034/2807.

Wahyuni DS. 2012. Hubungan kondisi fisik rumah dan karakteristik pasien dengan kejadian tuberculosis paru
BTA positif di puskesmas Ciputat Kota Tangerang Selatan tahun 2012. BIMKM. 2012; 1(1):1-8.

Suarni H. 2009. Faktor yang berhubungan dengan kejadian penderita TB paru BTA positif di Kecamatan Pancoran Mas Kota Depok bulan Oktober tahun 2008 - April Tahun 2009 (skripsi). Jakarta: Fakultas Kesehatan Masyarakat Universitas Indonesia.

Limbu, Ribka, Marni. 2006. Peran keluarga sebagai pengawas minum obat (PMO) dalam mendukung proses pengobatan penderita TB Paru di wilayah kerja puskesmas Baumata Kecamatan Taebenu Kabupaten Kupang.

Hannan, M \& Hidayat, S. 2013. Peran Keluarga Dalam Perawatan Penderita Tuberculosis Paru Di Kecamatan Gapura Kabupaten Sumenep. MKM Vol.02 No. 01 Juni2007. Sumenep :Unija, dari :http//download.portalgaruda.org/art icle 